\title{
Left Posterolateral Middle Peripheral Zone of Prostate
}

National Cancer Institute

\section{Source}

National Cancer Institute. Left Posterolateral Middle Peripheral Zone of Prostate. NCI

Thesaurus. Code C128601.

The region of the prostate that is located on the anatomical left side of the posterolateral portion of the middle division of the peripheral zone. 